\title{
EGFR-GRB2 Complex
}

National Cancer Institute

\section{Source}

National Cancer Institute. EGFR-GRB2 Complex. NCI Thesaurus. Code C116967.

A protein complex comprised of two epidermal growth factor receptor (EGFR) family proteins, and one or two growth factor receptor-bound protein 2 (GRB2) adaptor proteins. These complexes form after epidermal growth factor (EGF) family lig ands bind to EGFR proteins. Ligand binding triggers receptor dimerization and cross-receptor tyrosine phosphorylation, which allows the $\mathrm{SH} 2$ domains of each growth factor receptorbound protein 2 to form a non-covalent bond with the phosphorylated EGFR proteins. 